\title{
The future of the patient and the patient of the future
}

John Yaphe, MD*

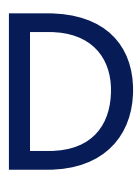

ecember is a good month for looking back at the past and forward to the future. That can help us to function in the 'here and now'. This is also a good time to reflect on the past three years' experience of the current editorial team of this journal. We have explored a number of hot topics in family medicine on these pages and it might be helpful to think now where this is leading us.

Computers in the consulting room, family medicine research capacity, evidence based medicine, the value of case reports, the importance of access, the role of the family, training for palliative care, risks and benefits of sub-specialization, the arrival of refugees, the meaning of narrative medicine, threats and benefits of performance assessment, risks of medicalization, and the new role of quaternary prevention are some of the topics we have explored in this journal over the past three years.

The thread that joins these topics is an unwavering concern for the welfare of our patients, despite the challenges we face from rapid changes in modern society and the attractions of new technology in medicine.

Looking forward to the next three years and the tasks to be faced by the incoming editorial board, we might reflect on some points that can show us the way forward in this Brave New World.

While maintaining our patient-centred stance, we might imagine what the patient of the future will be like. That might help us to adapt as a profession to meet the new challenges.

Bertalan Mesko, a physician who calls himself a 'medical futurist', says that patients of the future will be involved in their own health management by obtaining data from hand held monitors of pulse, respiration and other physical parameters. The future patient will seek partnership rather than a paternalistic relationship from the doctor. Patients will be part of health communities like the ones that now exist on line on social

*Associate Professor, Community Health, School of Medicine, University of Minho media sites. Patients will have access to their medical records to allow for sharing of data and obtaining multiple professional opinions. Finally, he predicts that patients will want to use their data for prediction and prevention to control their health. ${ }^{1}$

Terry Thurston, a nurse involved in patient safety, argues that patients in the future, especially those born in the post-war baby boom generation, will be well educated, technologically wise, getting most of their care outside hospital, health focused, and desiring care that is dignified, personal, and private. ${ }^{2}$

The cardiologist Eric Topol sees a future for the patient largely based on hand-held monitoring technology, in the hands of patients, linked to specialist interpretation, with advice available in distant centres. In his book 'The Patient Will See You Now' he predicts a bright future with smart beds, smart rooms, and smart hospitals. One wonders if this vision will also include smart doctors. $^{3}$

His bias is understandable given that he works in a highly technological profession (high tech, low touch) that remains disease-centred. We continue to work as family doctors, in the community, where most conditions have low incidence and low prevalence. We need to explore a different kind of future with less technological reliance (low tech, high touch). The average family doctor in Portugal, with a list size of 1,700 patients, may expect to see only one or two patients per year from their list with an acute myocardial infarction. ${ }^{4}$ Does this justify the medicalization inherent in the issuing of handheld or wrist-strapped monitors to the relevant populations at risk? Some good qualitative studies on patients needs and wishes along with careful calculations of cost-effectiveness need to be done to assess this scenario.

Some things will probably not change in the patient of the future. The empowered patient, who is interested in shared decision making, even after careful monitoring of blood pressure, blood sugar, peak expirato- 
ry flow, and oxygen saturation at home, will still have familiar needs. Our future patient will probably still want to be cared for by a compassionate physician. Our patient will seek the wise counsel of an experienced advisor who knows them in their natural context. They will desire a listening ear from someone who respects their dignity and privacy. They will require simple interpretation of cold data so that they can make sense of their lives. They will seek explanations as well as meaning. They will sometimes require a silent witness to their suffering. They will need to know that their doctor cares. All this transcends the capacities of even the smartest of 'smart' telephones.

With regard to the some of the other core concepts we have explored on these pages, the patient of the future will probably still value continuity of care with the same, familiar provider. Teams and electronic medical records will provide institutional continuity but there will be no substitute for "the doctor who knows me".

In the same way, electronic communication media will provide easy access to medical care through text messages, electronic mail, voice, video, the transmission of biological monitoring data, or other formats. However, easy access to face-to-face care, at times and places that are convenient to the patient, will still be one of the standards by which the quality of care is measured.

The computer remains an elephant in the room, or at least on the doctor's desk. Miniaturization of the machine will not shrink the issues we face in improving doctor-patient communication. Some issues are independent of the recording system used. Good doctors were good listeners in the age of paper records just as they are in the era of electronic medical records. The converse is also true about poor listeners. Doctors of the future will hopefully be trained, qualified, and continually assessed on the strength of their empathic listening skills. Patients and practitioners will likely share electronic medical records.

Our systems of performance assessment are likely to change as well. Even in the brief period we have struggled with performance indicators in primary care, we have heard critical voices calling for reform. We can no longer focus on process items and intermediate, disease-oriented outcomes. We need to develop valid, reliable, feasible indicators that are sensitive to change and that reflect real improvements in health and the quality of life of patients. The future should see more patient involvement in the establishment of these new indicators.

Other social changes we have discussed such as the sudden influx of large numbers of refugees and other immigrants in a volatile world will require adaptations in our education and our daily practices. Similarly, slower social changes in the structure and functions of the family will demand flexibility on our part as caregivers. We will need to develop new tools to face these challenges.

Our profession has been at the forefront of many social changes and has responded adequately and even creatively to change. We can be confident that family medicine has a central role to play as health and disease, the medical profession, the family, and society continue to change. We believe that a person-centered approach will remain at the heart of that change.

\section{REFERENCES}

1. Mesko B. Five expectations for patients about the future of medicine [Internet]. The Medical Futurist.com; 2016. Available from: http://medicalfuturist.com/five-expectations-for-patients-about-the-future-ofmedicine/

2. Thurston T. The patient of the future [Internet]. Health Care Design; 2012 Sep 5.Available from: http://www.healthcaredesignmagazine.com /blogs/bsa-lifestructures/patient-future

3. Topol E. Patient of the future: new 'smart' tools will empower millions to diagnose and manage their condition at home [Internet]. U.S. News; 2015 Sep 2. Available from: http://health.usnews.com/healthnews/hospital-of-tomorrow/articles/2015/09/02/patient-of-the-future

4. Yazdanyar A, Newman AB. The burden of cardiovascular disease in the elderly: morbidity, mortality, and costs. Clin Geriatr Med. 2009;25(4): 563-77.

\section{CONFLICT OF INTEREST}

None.

ENDEREÇO PARA CORRESPONDÊNCIA

yonahyaphe@hotmail.com 